\title{
Erratum
}

\section{Multiresolution Analysis of Heart Rate Variability as Investigational Tool in Experimental Fetal Cardiac Surgery}

\author{
Mauro Grigioni, Adriano Carotti, Costantino Del Gaudio, Umberto Morbiducci, \\ SONIA B. Albanese, and GiUSEPPE D'AVENIO
}

(Published online: 1 June 2006)

In the Materials and Methods section (sub-section Wavelet Analysis) just above Equation 4, the following line printed incorrectly: The instantaneous power for each decomposition level was computed as follows: ${ }^{28}$
The line should have read: The instantaneous power for each decomposition level was computed as follows: ${ }^{27}$

Originaly published Online First March 15, 2006, DOI: 10.1007/s10439-006-9084-x 